\title{
TETANUS SITUATION IN PAKISTAN; COMPARISON OF MEDICAL VERSUS SURGICAL MANAGEMENT.
}

1. Associate Professor Surgery Unit II , LUMHS, Jamshoro.

2. Assistant Professor Surgery Unit IV LUMHS, Jamshoro.

3. Assistant Professor, Surgery Unit II LUMHS, Jamshoro

4. Professor of Surgery Unit II

LUMHS, Jamshoro.

5. Incharge Surgical Unit - II LUMHS, Jamshoro

Correspondence Address:

Dr. Altaf Ahmed Talpur

Flat No: A- 202, Fort Sultan

Apartments,

Opposite Airport Telephone

Exchange,

Main Shahra-e-Faisal, Karachi,

Pakistan.

altafktalpur@yahoo.com

Article received on:

18/02/2016

Accepted for publication:

09/04/2016

Received after proof reading:

$26 / 05 / 2016$

\section{Dr Altaf Ahmed Talpur', Dr Abdul Rasheed Surahio², Dr Abdul Salam Memon ${ }^{3}$, Professor Afzal Junejo ${ }^{4}$, Prof. Akmal Jamal ${ }^{5}$}

ABSTRACT... Objectives: To determine demographic and clinical profile of Tetanus patients and to highlight various management strategies as well as the outcome of the tetanus patients. Background: Tetanus, a preventable disease still found in high frequency in developing world. Globally one million cases are recorded annually. This disease found more frequently in patients who are either non vaccinated or partially immunized. Diagnosis of Tetanus is solely made on clinical grounds with no definitive investigation available to confirm the diagnosis. Mortality of Tetanus is directly related to the grade of tetanus at presentation. Study Design: Descriptive observational study. Setting: Public and private sector hospitals of Hyderabad, Pakistan. Period: 1st Nov 2008 to $31^{\text {st }}$ Oct 2015. Materials \& methods: It includes patients of either sex above the age of 13 years who were clinically diagnosed as case of Tetanus. Data was collected for variables related to demography, incubation period, site of injury, history of tetanus vaccination, co morbidity, stage of presentation, management \& outcome of treatment, complications \& mortality. Results: Total 131 patients of Tetanus were finally analyzed. It includes 124 (94.65\%) male and $07(5.34 \%)$ female patients with mean age of 34.06 years. $69(52.67 \%)$ were farmers by occupation. History of injury was present in 109(83.20\%) patients \& incubation period was $<10$ days in $39(29.77 \%)$ patients. Lower limb was the commonest site of injury noted in $86(65.64 \%)$ patients. Tetanus immunization history was positive in $63(48.09 \%)$ patients. Among the clinical findings, generalized bodyache or stiffness with backache was noted in 107(81.67\%) patients, restricted mouth opening in 101 (70.09\%) patients. Grade I Tetanus was noted in 63(48.09\%) patients. Complications of tetanus were noted in $43(32.82 \%)$ patients. Mortality rate was noted in $33(25.19 \%)$ patients. Mean hospital stay was $12.3 \pm 9.0$ days. Conclusion: Tetanus is found in significant frequency in our setup which carries substantial morbidity and mortality.

Key words: Tetanus, demography, clinical profile, management

\section{INTRODUCTION}

Tetanus is a potentially preventable, infective disease. Its incidence has been significantly reduced in many countries of the world. In one estimation approximately one million cases of tetanus are recorded annually around the world. Frequency of tetanus found to be higher in developing countries especially Asia, Africa, and Middle East where immunization is not available to majority of people for various reasons. Mortality from tetanus approaches close to fifty percent in developing countries like Pakistan. ${ }^{1,2}$

Tetanus occurs sporadically and is found to affect either to non-vaccinated people or to people who are unable to maintain their immunity status through booster doses of vaccine. In order to get protection against tetanus it is necessary to vaccinate people at an earlier age to develop immunity with subsequent maintenance of adequate immunity by means of appropriately timed boosters. ${ }^{3,4}$

Onset period of symptoms of tetanus is highly variable \& it ranges from two days to several weeks. In patients who have shorter duration of onset of symptoms after sustaining injury they usually present with higher grades of tetanus at presentation. The presenting symptoms are usually lock jaw, board like rigid abdominal wall, 
arching of back and spontaneous spasm of the muscles of the body which is triggered by the movements of the patient or by noise. When Autonomous nervous system is involved, patients may develop cardiovascular complications such as fluctuations of blood pressure and cardiac arrhythmias. $^{5}$

The diagnosis of tetanus is based on clinical ground as sensitivity of culture reports of patients with tetanus is not good \& it is not offered routinely. Also methods $s$ to detect circulating level of potential toxin of tetanus is not routinely available \& also not employed commonly. The patient of tetanus usually dies of exhaustion, asphyxia, aspiration pneumonia or autonomic nervous system instability.

The aim of this study was to evaluate demographic and clinical profile of Tetanus patients and to know various management strategies as well as the outcome of the tetanus patients.

\section{MATERIALS AND METHODS}

This was a descriptive observational study conducted at public and private sector hospitals of Hyderabad, Pakistan from 1st Nov 2008 to $31^{\text {st }}$ Oct 2015. All patients of either sex above the age of 13 years who were clinically diagnosed as case of Tetanus were included in the study. Patients below the age of 13 years, already diagnosed cases of Epilepsy were excluded. Patients of significant cardiac dysfunction, hepatic, respiratory and renal impairment were excluded from the study. Patients who did not consented for study or lost to follow-up were also excluded.

These patients were admitted in ward. Detailed history was taken from these patients especially in data related to age, sex, symptomatology, co morbid illness, history of trauma or needle injury or wound anywhere on body \& history of vaccination. Thorough examination was performed with special focus on variables like fever, muscle spasm, opisthotonus, rigid abdominal wall muscles, lock jaw. Investigations like Arterial blood gases, complete blood count, blood sugar, blood urea, serum Electrolytes, HBsAg, Anti HCV antibodies, LFT's, PT with INR, APTT and where required ECG and chest $\mathrm{x}$-ray were performed. Diagnosis was made and patients or their attendants were briefed about the diagnosis. Patients or their attendants were informed about the study and permission was granted. They were assured that their participation is voluntary with no harms to them in terms of getting due treatment. They were also given right to withdraw from study without putting any reasons.

Severity of tetanus was classified according to the system reported by Ablett. ${ }^{4}$

Treatment was started. Patients of grade II, III \& IV tetanus were admitted in intensive care unit, kept nothing orally, intravenous fluids started \& Nasogastric tube \& Foleys catheter passed. Patients with Grade I Tetanus were kept in general ward \& put on liquid diet. All patients were given intravenous Antibiotics (Amoxicillin with Clavulinic acid 1.2 grams \& Metronidazole three times a day) for 07 days, antispasmodics, sedatives like Diazepam derivatives \& analgesics. Antiepileptic drugs like Phenytoin or barbiturates were given to patients who developed fits. Magnesium Sulphate was given to patients who did not respond to routine medications for control of spasms. Patients who developed lower respiratory infection or inhalational pneumonitis were put on Imipenem 500mg three times a day. Tetanus Immunoglobulin \& Tetanus Toxoid was given. Patients who were unable to maintain Oxygen saturation were given Oxygen or ventilator support. In patients with uncontrolled fits Tracheostomy was made. Debridement of wound was performed in patients with contaminated wound followed by daily dressing. Patients were discharged from hospital once they tolerated feed well \& their spasm or fits are controlled on oral medication. Follow-up visits were advised at 10 days, 1 \& 3 months.

Data was collected on preformed proforma for variables related to demography, clinical details, stage of presentation, co morbid illness, site of 
injury \& history of tetanus vaccination, incubation period, management \& outcome of treatment, including related complications \& mortality.

The data were analyzed using Statistical package for social sciences version 16 (Chicago IL, USA). Descriptive statistics were applied on demographic variables like age, gender. Qualitative variables were presented as Mean and standard deviation like age. Qualitative variables were presented in percentage and frequencies like incubation period, co morbid illnesses, Complication developed in patient and mortality rate.

Key Definitions: ${ }^{4}$

Incubation Period: Time duration between the inoculation of the wound and the onset of the symptoms of Tetanus.

\section{RESULTS}

During this 07 years period, Initially 136 patients of Tetanus were included in study. However, 05 patients did not complete the follow up \& were excluded from study. Thus a total of 131patients of Tetanus were finally analyzed in the study.

It includes 124 (94.65\%) male and 07 (5.34\%) female patients. Mean age of patients was 34.06 years with standard deviation \pm of 12.124 years. The youngest patient in this study was 14 years \& oldest of 67 years.

Regarding occupation; 69 (52.67\%) were farmers by occupation. (Table-l).

History of injury was present in 109(83.20\%) patients \& incubation period was $<10$ days in $39(29.77 \%)$ patients. Lower limb was the commonest site of injury noted in $86(65.64 \%)$ patients. (Table-I).

Tetanus immunization history was positive in 63 (48.09\%) patients (Table-l).

\begin{tabular}{|l|c|}
\hline \multicolumn{1}{|c|}{ Characteristics } & N \& \% of patients \\
\hline Age of patients $<40$ years & $93(70.99 \%)$ \\
$>$ 40 years & $38(29.00 \%)$ \\
\hline Sex Male & $124(94.65 \%)$ \\
Female & $07(5.34 \%)$ \\
\hline Occupation & \\
Farmer & \\
Laborer & $69(52.67 \%)$ \\
Miscellaneous patients including & $43(32.82 \%)$ \\
patients of RTA & $12(9.16 \%)$ \\
\hline Positive history of injury & $109(83.20 \%)$ \\
\hline Incubation period < 10 days & $39(29.77 \%)$ \\
\hline$>10$ days & $70(53.43 \%)$ \\
\hline Site of injury lower limb & $86(65.64 \%)$ \\
Upper limb & $05(3.81 \%)$ \\
Multiple injuries & $18(13.74 \%)$ \\
\hline Tetanus immunization positive & $63(48.09 \%)$ \\
Negative & $08(6.10 \%)$ \\
Not known & $60(45.80 \%)$ \\
\hline Table-l. Demographic characteristics of patients with \\
\hline \multicolumn{2}{|c|}{ Tetanus ( $\mathrm{n}=131)$} \\
\hline
\end{tabular}

Among the clinical findings generalized bodyache or stiffness with backache was noted in $107(81.67 \%)$ patients, restricted mouth opening in $101(70.09 \%)$ patients. (Table-II)

Co morbid illness was noticed in $29(22.13 \%)$ patients. (Table-II)

\begin{tabular}{|c|c|}
\hline Clinical features & N \& $\%$ of patients \\
\hline $\begin{array}{l}\text { Restricted mouth opening (Trismus) } \\
\text { Generalized body ache \& stiffness } \\
\text { Neck rigidity } \\
\text { Dysphagia } \\
\text { Rigid Abdominal wall } \\
\text { Respiratory distress } \\
\text { Fits } \\
\text { Fever }\end{array}$ & $\begin{array}{c}101(70.09 \%) \\
107(81.67 \%) \\
93(70.99 \%) \\
71(54.19 \%) \\
74(56.48 \%) \\
65(49.61 \%) \\
35(26.71 \%) \\
61(46.56 \%)\end{array}$ \\
\hline $\begin{array}{l}\text { Co morbid illnesses } \\
\text { Diabetes Mellitus } \\
\text { Hypertension } \\
\text { IHD } \\
\text { Bronchial Asthma }\end{array}$ & $\begin{array}{l}29(22.13 \%) \\
08(6.10 \%) \\
08(6.10 \%) \\
04(3.05 \%) \\
09(6.87 \%)\end{array}$ \\
\hline $\begin{array}{l}\text { Table-II. Characteristics of clini } \\
\text { morbid illness of Patient }\end{array}$ & $\begin{array}{l}\text { sentation \& co } \\
\text { Tetanus }\end{array}$ \\
\hline
\end{tabular}


Investigations of these patients revealed Hemoglobin level of less than $10 \mathrm{~g} / \mathrm{dl}$ in 89 $(67.93 \%)$ patients. Total leukocytes count more than $11000 /$ dl was seen in $73(55.72 \%)$ patients. Arterial blood gases analysis was performed in 57 (43.51\%) patients who developed fits or unable to maintain oxygen saturation. It showed respiratory alkalosis in 53(40.45\%) patients. Chest $X$ ray was performed in 71 (54.19\%) patients. It showed chest infection or aspiration pneumonia in $16(12.21 \%)$ patients.

Complications were noted in $43(32.82 \%)$ patients' of tetanus \& these patients were shifted to intensive care unit for further management (Table-III). It includes Autonomic dysfunction in 18(13.74\%) patients, respiratory tract infection in 16(12.21\%) patients, renal impairment in $01(0.76 \%)$, lleus in 04(3.05\%) \& sepsis in 04(3.05\%) patients.

Mechanical ventilation was required in 34(25.95\%) patients \& Tracheostomy in 12(9.16\%) patients of Tetanus.

Mortality rate was noted in $33(25.19 \%)$ patients. Mortality was noticed in $01 / 63$ (1.58\%) patient of grade I disease which died due to cardiac dysfunction while it was noted in 32/68 (47.05\%) of grade II \& above disease. (Table-III).

\begin{tabular}{|l|c|}
\hline Grades of tetanus & N \& \% of Patients \\
\hline Grade I & $63(48.09 \%)$ \\
Grade II & $38(29.00 \%)$ \\
Grade III & $25(19.08 \%)$ \\
\hline Grade IV & $05(3.81 \%)$ \\
\hline Complications & $43(32.82 \%)$ \\
RTI \& aspiration pneumonitis & $16(12.21 \%)$ \\
\hline Autonomic dysfunction leading to & $18(13.74 \%)$ \\
cardiac dysfunction & $04(3.05 \%)$ \\
Paralyticus lleus & $01(0.76 \%)$ \\
\hline Functional renal impairment & $04(3.05 \%)$ \\
\hline Sepsis & $33(25.19 \%)$ \\
\hline Mortality with Tetanus $(n=131)$ \\
\hline \multicolumn{2}{|c|}{ Table-III. Grades, complications \& mortality of patients } \\
\hline \multicolumn{2}{|c|}{} \\
\hline
\end{tabular}

Mean hospital stay was $12.3 \pm 9.0$ days with a range of 3-34 days.

\section{DISCUSSION}

Tetanus is one of the major health issue recognized worldwide especially in underdeveloped world which is reported to be around one million patients in a year. ${ }^{8}$ In western nations prevalence of Tetanus has significantly decreased due to implementation of effective vaccination programme. Also the mortality associated with Tetanus has reduced by the application of recent techniques in the treatment of patients with Tetanus. $^{3}$

In this study 131 patients of tetanus were registered during 07 years study period with $94.65 \%$ were male \& $71 \%$ of them were below the age of 40 years. Almost same pattern of disease demography is noted in study by lau LG et al at Malaysia. ${ }^{9}$ This tendency of younger age group patients noted in both studies may be due to ineffective \& improper application of immunization campaign in this countires. ${ }^{3}$ For assessment of immunization status a survey was conducted in United States that shows high prevalence of Tetanus among in older age patients which has been related to presence of reduced level of protective antibodies against Tetanus in these group of patients. ${ }^{6}$ Amare A et al in Ethopia ${ }^{10}$ noted that amongst Tetanus patients $75 \%$ were male with $92 \%$ patients were less than 50 years of age.

This disease has notably been noticed in population who work in outdoor fields especially in farmers \& laborers. This same pattern of disease distribution has been found in our society. However study at Nigeria by Fasunla AJ reported surprisingly high proportion of disease among students and civil servants. ${ }^{11}$

Positive Tetanus immunization status was noticed in $48.09 \%$ patients of this study. In study at Nawabshah by Khaskheli MS et $\mathrm{al}^{3}$ they found that $72.7 \%$ of their patients were either not vaccinated or not aware of their immunization status against Tetanus while in studies at Ethopia $^{10}$ \& Saudi Arabia ${ }^{12}$ none of their Tetanus patients were vaccinated for tetanus priory. Status of immunization against tetanus in this 
country among adult population is not properly structured and no well recognized schedule is currently available in this regard. ${ }^{13}$

In this study history of injury was present in $83.20 \%$ patients with incubation period was $<10$ days in $29.77 \%$ patients. Lower limb was the commonest site of injury noted in $65.64 \%$ patients. Fawibe AE at Nigeria ${ }^{14}$ found site of injury in $68.6 \%$ patients with $57.1 \%$ of them sustain this on lower limbs. In a study at Saudi Arabia by Lubbade $\mathrm{EH}$ et $\mathrm{al}^{12}$ they found positive history of injury in $72.7 \%$ their patients which were commonly sustained at lower limbs. However in contrast to commonly found pattern of lower limb as the most common site of injury among Tetanus patients Joshi et al ${ }^{15}$ in their study at Nepal reported upper limbs as the most common portal of entry. Reasons for high prevalence of Lower limb injury leading to Tetanus is due to the fact that organisms reside in soil \& most people sustain trauma at lower limbs which are at increased risk to contamination by soil. ${ }^{2}$

Tetanus is essentially a clinical diagnosis with no definite investigation is available to confirm it. In this study most common symptom was restricted mouth opening noted in $93 \%$ patients followed by generalized body ache with stiffness, Neck rigidity \& Dysphagia in 98\%, 85\% \& 67\% patients respectively. In study from India by Marulappa VG et $\mathrm{al}^{16}$ the most common presenting symptoms were trismus in $95.7 \%$, neck stiffness in $89.3 \%$, body spasms/stiffness in $73 \%$ and Dysphagia in $38.9 \%$ patients. Almost same pattern of presenting symptoms were noticed in studies from $\mathrm{KSA}^{12}$, Nawabshah ${ }^{2}$ \& Dubai. ${ }^{4}$

In this study $48.09 \%$ patients presented in Grade I, 29.00\% in Grade II, $19.08 \%$ in Grade III \& 3.81\% patients IV disease. In study from Nigeria by Fawibe et $\mathrm{al}^{14}$ mild tetanus was noticed in $2.9 \%$ patients, moderate in $25.7 \%$, severe in $60.0 \%$ \& very severe in $11.4 \%$ patients.

Among the confounding factors indicators of increased morbidity \& mortality among Tetanus patients, raised TLC count was noticed in $55.72 \%$ patients \& $12.21 \%$ patients had abnormal Chest $X$ ray findings suggestive of chest infection or aspiration pneumonia in this study. In study from $\mathrm{KSA}^{12}$ significantly raised Creatinine kinase level was noticed in all patients \& raised Lactate dehydrogenase in most patients.

Complications of tetanus were noted in $32.82 \%$ patients of this study. Most common amongst them were Autonomic dysfunction in 13.74\% patients \& respiratory tract infection in $12.21 \%$ patients. Almost same pattern of complications were seen in study from Dubai by Younas $\mathrm{NJ}$ et al. ${ }^{4}$ In study from Tanzania by Chalya et $\mathrm{al}^{17}$ complications were documented in 54.9\% patients which includes respiratory complications in $32.1 \%$ \& cardiovascular in $19.6 \%$ patients. Complications of Tetanus significantly increase mortality rate of tetanus patients. Therefore great focus \& effort is needed to prevent complications of Tetanus which is possible only by making early diagnosis and provision of effective treatment as mortality increases as the grade of presentation increases.

Spasms of Tetanus can only be controlled by providing heavy sedation with ventilatory support to them. In this study mechanical ventilation was provided to $25.95 \%$ patients \& Tracheostomy to $9.16 \%$ patients. In study at $\mathrm{KSA}^{12} 81.81 \%$ of Tetanus patients were put on ventilation support \& in study at Nawabshah ${ }^{2}$ they mentioned use of Tracheostomy in $36.4 \%$ of their Tetanus patients. Death ratio among tetanus patients who presented in higher grades can be significantly reduced by the use of Tracheostomy as these patients usually die of asphyxia from laryngeal muscle spasm and aspiration. ${ }^{18}$ An Indian study mentioned Tracheostomy and mechanical ventilation in $74 \%$ and $45 \%$ of Tetanus patient's respectively. ${ }^{18}$

The outcome of patients with tetanus has been reported variably \& is significantly affected by many factors which include age grade of presentation, development of complications, presence of co morbid factors \& presence of effective tools of treatment. ${ }^{17}$ Literature reports 
mortality from tetanus in adult population ranges between $10-50 \%$ which in neonates approaches to $90-95 \% .{ }^{19}$ In this study mortality rate was $25.19 \%$, however Sanya et al $^{19}$ from Nigeria mentioned $64 \%$ mortality rate in their study without availability of intensive care facilities. Al-Kaabi et $\mathrm{al}^{20}$ in Saudi Arabia found $10 \%$ mortality rate. They correlated this low mortality rate to early and aggressive treatment of their Tetanus patients in the intensive care unit.

The mean duration of hospitalization was $12.3 \pm 9.0$ days with a range of 3-34 days. Chalya et al from Tanzania ${ }^{17}$ observed average ICU stay of 19.3 days with the range of 1-26 days.

The limitation of this study was inadequate \& improper medical record.

\section{CONCLUSION}

Tetanus is still found as high prevalent disease in our society as noticed in this study despite the fact its incidence can be reduced significantly by implementation of effective \& proper tetanus immunization schedule \& health awareness among population regarding Tetanus thereby decrease burden on health resources. However once inflicted it needs to be diagnosed at an early stage as higher grades of presentation \& presence of complications are associated with more mortality from Tetanus.

Copyright(C) 09 Apr, 2016.

\section{REFERENCES}

1. Wasay M, Khatri IA, Salahuddin N. (Editorial) Tetanus and rabies eradication in Pakistan; a mission not impossible. J Pak Med Assoc 2008; 58(4): 158159.

2. Khaskheli MS, Khuhro BA, Jamali AH. Tetanus: still a killer in adults. Anesth, pain \& intensive care 2013; 17(2): $149-153$.

3. Edlich RF, Hill LG, Mahler CA, Cox MJ, Becker DG, Horowitz $\mathrm{JH}$ : Management and prevention of tetanus. J Long Term Eff Med Implants 2003, 13(3):139-54.

4. Younas NJ, Abro AH, Das K, Abdou AMS, Ustadi AM, Afzal S: Tetanus: Presentation and outcome in adults. Pak J Med Sci 2009, 25(5):760-65.

5. Davilla CAM, Davilla DF, Donis JH, Gonzalo X. Autonomic nervous system dysfunction in children with severe tetanus: dissociation of cardiac and vascular sympathetic control. Braz J Med Biol Res 2003; 36: 815-19.

6. Brian SS, Henry FC. Bacterial, Chlamydial Infections. In: Stephen JM, Maxine AP. Current Medical Diagnosis and Treatment, $\mathbf{4 8}^{\text {th }}$ edi. Mc Graw Hill Lange, 2009:12651266.

7. Allen CMC, Lueck CJ, Dennis M. Tetanus. In: Nicholas AB, Nicki RC, Brian RW. Davidson's Principles and Practice of Medicine, $2^{\text {th }}$ eds. Elsevier 2006:12321233.

8. Anuradha S. Tetanus in Adults-A Continuing Problem: An analysis of 217 Patients over 3 Years from Delhi, India, with Special Emphasis on Predictors of Mortality. Med J Malaysia 2006; 61(1): 7-14.

9. Lau LG, Kong KO, Chew PH. A ten year retrospective study of tetanus at a general hospital in Malaysia. Singapore Med J 2001; 42(8): 346-350.

10. Amare A, Yami A. Case-fatality of adult Tetanus at Jimma University Teaching Hospital, Southwest Ethiopia. Afr Health Sci. 2011 Mar; 11(1):36-40. PMID: 21572855.

11. Fasunla AJ: Challenges of Tracheostomy in Patients Managed for Severe Tetanus in a Developing Country. Int J Prev Med 2010, 1(3):176-81.

12. Lubbade EH, Khazindar AM, Ayub M. Tetanus experience in a public hospital in Western Saudi Arabia. saudi Medical Journal 2003; Vol. (12): 13251328.

13. Wasay M, Malik A, Fahim A, Yousef A, Chawla R, Daniel H, Rafay M, Azam I, Razzak J. Knowledge and attitudes about Tetanus and Rabies: A populationbased survey from Karachi, Pakistan. J P M A 2012; $62(4)$ : $378-38$.

14. Fawibe AE. The Pattern and Outcome of Adult Tetanus at a Sub-urban Tertiary Hospital in Nigeria. J Coll Physicians Surg Pak. 2010 Jan; 20(1):68-70. PMID: 20141700.

15. Joshi S, Agarwal B, Malla G, Karmacharya B. Complete elimination of tetanus is still elusive in developing countries: a review of adult tetanus cases from referral hospital in Eastern Nepal. Kathmandu Univ Med J; 2007, 5(3):378-81.

16. Marulappa VG, Manjunath $\mathrm{R}$, Mahesh Babu N, Maligegowda L. A Ten Year Retrospective Study on Adult Tetanus at the Epidemic Disease (ED) Hospital, Mysore in Southern India: A Review of 512 Cases. J Clin Diagn Res. 2012 Oct; 6(8):1377-80. 
17. Chalya LP, Mabula JB, Dass RM, Mbelenge N, Mshana SE, Gilyoma JM. Ten-year experiences with Tetanus at a Tertiary hospital in Northwestern Tanzania. A retrospective review of 102 cases. World J Emerg Surg 2011, Jul 8; 6:20. PMID: 21740539.

18. Bhatia R, Parbharkar S, Grover VK: Tetanus. Neurol India 2002, 50:398-407.
19. Sanya EO, Taiwo SS, Olarinoye JK, Aje A, Daramola $\mathrm{OO}$, Oguniyi A. A 12-year review of cases of adult tetanus managed at the University College Hospital, Ibadan, Nigeria. Trop Doct 2007; Jul; 37(3):170-3. PMID: 17716509.

20. Al-Kaabi, Scimgeour EM, Louon A, Al Riyami BM. Tetanus: a clinical review. Saudi Med J 2001; Jul; 22(7):606-9. PMID: 11479643.

\section{CORRECTION}

\section{INCORRECT}

DR. AHMAD SHERJIL, MBBS, FCPS (PAEDS)

Child Specialist,

PNS Rahat Hospital, Karachi

DR. AHMAD SHERJIL, MBBS, FCPS (PAEDS)

Child Specialist,

PNS Rahat Hospital, Karachi
DR. COL. JAVAID IQBAL, MBBS, FCPS (GEN. MED)

Head of Medical Department

PNS Rahat Hospital, Karachi

\section{CORRECT}

DR. COL. JAVED IQBAL, MBBS, FCPS (GEN. MED)

Head of Medical Department

PNS Rahat Hospital, Karachi

\section{PREVIOUS RELATED STUDY}

Sajid Sheikh, Mohammmad Ajmal, A.G. Rehan, Muhammad Yousaf Shah. TREATMENT OF TETANUS; THE USE OF CONTINUOUS ATROPINE SULPHATE INFUSION (Original) Prof Med Jour 14(2) 312-317 Apr, May, Jun, 2007.

AUTHORSHIP AND CONTRIBUTION DECLARATION

\begin{tabular}{|c|l|l|l|}
\hline Sr. \# & \multicolumn{1}{|c|}{ Author-s Full Name } & \multicolumn{1}{|c|}{ Contribution to the paper } & Author=s Signature \\
\hline 1 & Dr Altaf Ahmed Talpur & $\begin{array}{l}\text { Conception, Design \& } \\
\text { Acquisition Data } \\
\text { Analysis \& Interpretation } \\
\text { of data } \\
\text { Drafting of article }\end{array}$ \\
3 & Dr Abdul Rasheed Surahio & Dr Abdul Salam Memon & Critical review of Article \\
4 & Professor Afzal Junejo & Final approval of Version & \\
5 & Prof. Akmal Jamal &
\end{tabular}

